\title{
3D NANOCOMPOSITE CHITOSAN/BIOACTIVE GLASS SCAFFOLDS OBTAINED USING TWO DIFFERENT ROUTES: AN EVALUATION OF THE POROUS STRUCTURE AND MECHANICAL PROPERTIES
}

\author{
Elke M. F. Lemos ${ }^{a}$, Patrícia S. O. Patrício ${ }^{\mathrm{b}}$ e Marivalda M. Pereira ${ }^{\mathrm{a} *}$ \\ aDepartamento de Engenharia Metalúrgica e de Materiais, Universidade Federal de Minas Gerais, 31270-901 Belo Horizonte - \\ MG, Brasil

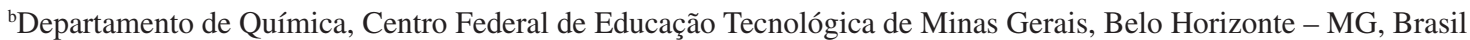

Recebido em 03/11/2015; aceito em 07/01/2016; publicado na web em 18/03/2016

\begin{abstract}
Porous synthetic substrates are developed through tissue engineering technologies to grow new tissue, restoring the function of tissue or an organ. For bone regeneration, these scaffolds must support the dynamic load exerted on this tissue, achieved primarily by increasing their compression strength, as established in the literature. The aim of this paper was to incorporate an inorganic composite bioactive glass $\left(60 \% \mathrm{SiO}_{2}-36 \% \mathrm{CaO}-4 \% \mathrm{P}_{2} \mathrm{O}_{5}\right)$ as a reinforcing agent in mechanical $3 \mathrm{D}$ scaffolds that must remain porous. Two strategies were adopted: a co-precipitation method to obtain a nanoparticulate dispersion of bioactive glass (BGNP) and a sol-gel method to combine a bioactive glass solution (BG) with a previously prepared chitosan polymer solution. Moreover, a lyophilization process was also used, generating highly porous scaffolds. Various aspects of the scaffold were evaluated, including the morphology, orientation and size of the pores, and mechanical strength, as obtained using the two synthetic methods. The data for compressive strength revealed increased strength after the incorporation of bioactive glass, which was more pronounced when utilizing the nanoscale bioactive glass.
\end{abstract}

Keywords: porous scaffolds; bioactive glass; nanoparticles; lyophilization.

\section{INTRODUCTION}

For bone tissue engineering, composites made from polymers and bioactive glass are of great interest when using nanoscale synthetic methods to improve the mechanical and biological properties. The substantial advantages of systems containing nanoscale bioactive glass have been demonstrated in recent publications. ${ }^{1-3}$ The nanometric particles have high surface areas and can form an interface that performs better when composited with porous polymer matrix. Introducing an appropriate percentage of nanometric bioactive glass particles in polymeric materials can increase the mechanical strength of the polymeric material. Furthermore, bioactive glass with a nanoscale surface area improves the adsorption and bioactivity. Evidence suggests that tissues, such as bone or teeth, deposit or mineralize faster when these tissues remain in contact with the nanoscale particles, increasing bone formation, as well as cell adhesion and proliferation. In recent research combining nanoscale bioactive glass particles or fibers and biodegradable polymers have become successful in bioactive composite materials. ${ }^{1,4-12}$ The high porosity is desirable in scaffolds that allow cell migration, tissue growth and eventual vascularization. ${ }^{13}$ However, this type of pore structure suffers from a low mechanical strength due to the high, although necessary, concentration of pores. The mechanical properties of porous scaffolds are crucial, especially with regard to the regeneration of hard tissue such as bone, which must support a load and meet specific mechanical needs while stimulating bone regeneration. The shape or configuration of the hard tissue is an important aspect of their function, and in such cases, the processing techniques used for the porous scaffolds for preparing structures with irregular three-dimensional geometries. ${ }^{14}$ In this work, composite porous scaffolds containing chitosan, PVA and bioactive glass and reticulated with glutaraldehyde were successfully obtained via a lyophilization method. This method has been successfully used to synthesize materials for bone tissue engineering because they can form a highly porous scaffold. A polymeric 3D composite scaffold can be produced with a high porosity (approximately 97\%) through this process. Porosity is a core requirement for the biomaterials used for tissue reconstruction because this quality promotes the growth, proliferation and nutrition of the cells in these tissues. Another important characteristic is the control over the rate of freezing for the polymer / solvent system, enabling the production of morphological variations in the porous structure of the scaffold and increases in the mechanical strength of the composite. ${ }^{15,16}$ The pores may be tubular or spherical structures with isotropic or anisotropic aspects. Porous scaffolds designed for bone tissue reconstruction must support a dynamic load, retaining enough strength to prevent crushing under physiological loads during integration and tissue regeneration. In the literature, hybrid composite materials, particularly nanocomposites, have been used to build porous scaffolds, generating specific properties that suit the demands of this tissue. ${ }^{2,15,17-22}$ Mechanical strength is a crucial factor in these scaffolds, which must be porous. In this study, the mechanical and morphological properties of porous hybrid scaffolds were evaluated using different contents of bioactive glass while comparing two different methods of incorporating the bioactive glass in the reticulated chitosan matrix.

\section{EXPERIMENTAL}

The commercial chitosan (high molecular weight and degree of deacetylation 75 - 85\%), tetraethylorthosilicate (TEOS, 98\%) and triethyl phosphate (TEP-99\%) were supplied by Sigma-Aldrich, and the ammonia $\left(\mathrm{NH}_{3}\right)$ and $\mathrm{Ca}\left(\mathrm{NO}_{3}\right)_{2} \bullet 4 \mathrm{H}_{2} \mathrm{O}(99 \%)$ were supplied by Synth. The composition of the bioactive glass was as follows: $60 \% \mathrm{SiO}_{2}, 36 \% \mathrm{CaO}$ and $4 \% \mathrm{P}_{2} \mathrm{O}_{5}(\% \mathrm{~mol})$. The $2.0 \%$ w/v solution of glutaraldehyde was obtained by diluting a $25 \% \mathrm{w} / \mathrm{v}$ solution (Sigma-Aldrich). 


\section{Bioactive glass solution preparation}

The bioactive glass precursor solution was obtained after the acid hydrolysis and polycondensation of tetraethylorthosilicate (TEOS $\left.\left(\mathrm{Si}\left(\mathrm{OC}_{2} \mathrm{H}_{5}\right)_{4}\right)\right)$, an alkoxide precursor of $\mathrm{SiO}_{2}$, specifically triethyl phosphate (TEP $\left.\left(\left(\mathrm{C}_{2} \mathrm{H}_{5} \mathrm{O}\right)_{3} \mathrm{PO}_{4}\right)\right)$ and $\mathrm{P}_{2} \mathrm{O}_{5}$ as an alkoxide precursor. The hydrolysis occurred after adding deionized water with a nitric acid catalyst. Calcium nitrate $\left(\mathrm{Ca}\left(\mathrm{NO}_{3}\right)_{2} \cdot 4 \mathrm{H}_{2} \mathrm{O}\right)$ was added as a precursor for $\mathrm{CaO}$.

\section{Preparation of the bioactive glass nanoparticle dispersion}

The method used to prepare the BGNPs was based on previous work, ${ }^{4,5}$ which combined the sol-gel and co-precipitation methods. In the first step, the TEOS and TEP precursors were hydrolyzed under acidic conditions. The precursors were dispersed in methanol and water, and the $\mathrm{pH}$ was adjusted to 1-2 using nitric acid. The mixture was stirred to obtain a transparent sol. During this second step, the transparent sol (monodisperse) was condensed separately in an alkaline solution. The sol was then added dropwise to deionized water containing ammonium hydroxide under vigorous mechanical agitation. The $\mathrm{pH}$ of the solution was adjusted to between 10 and 12 . After $12 \mathrm{~h}$ of mechanical stirring, the suspension was dried $50{ }^{\circ} \mathrm{C}$ in an oven to evaporate the ammonia (until $\mathrm{pH}<8$ ). Calcium nitrate was added with mechanical stirring, which continued for $24 \mathrm{~h}$. The dispersion was filtered through $0.22 \mu \mathrm{m}$ and $0.11 \mu \mathrm{m}$ Millipore filters; after filtering the dispersion, the dispersion was collected and stored for later use. The final appearance of the dispersion was a colorless liquid.

\section{Preparation of the hybrid Chi-BG scaffolds}

The hybrid scaffolds were obtained by mixing a $1 \% \mathrm{w} / \mathrm{v}$ chitosan solution with a precursor solution containing bioactive glass with one of the following compositions: $10 \mathrm{wt} \%, 20 \mathrm{wt} \%$ and $30 \mathrm{wt} \%$. These materials were then crosslinked with an amount of glutaraldehyde corresponding to $3 \mathrm{wt} \%$ of the total chitosan. The solution was poured into roller bottles and stored at room temperature for approximately 60 h. Afterwards, the bottles containing the hybrid gel were frozen at -20 ${ }^{\circ} \mathrm{C}$ and stored for an additional $60 \mathrm{~h}$. Subsequently, the bottles were immersed while frozen in liquid nitrogen at $-196{ }^{\circ} \mathrm{C}$ for 20 minutes and immediately placed on a freeze drying apparatus (Model: K105 Company Liotop - SP / Brazil) for 48 hours with a $-98^{\circ} \mathrm{C}$ condenser.

\section{Preparation of the hybrid nanocomposite Chi-BGNP scaffolds}

The nanocomposites scaffolds were obtained by dissolving $1 \%$ $\mathrm{w} / \mathrm{v}$ of chitosan powder in a BGNP dispersion under acidic conditions. The dispersion had one of the following compositions: $1 \mathrm{wt} \%$, $3 \mathrm{wt} \%, 5 \mathrm{wt} \%$ and $10 \mathrm{wt} \%$. The dissolution procedure involved the following steps: deionized water was added to the BGNP dispersion with mechanical stirring; the $\mathrm{pH}$ of the dispersion was measured and exceeded 7. Concentrated nitric acid was added until the $\mathrm{pH}=$ 2.5. Chitosan powder was added slowly while maintaining the $\mathrm{pH}$ below approximately 4 . After stabilization, the suspension was kept under mechanical stirring for $24 \mathrm{~h}$. Glutaraldehyde was added to the suspension, which was poured into a cylindrical bottles and kept at room temperature for $60 \mathrm{~h}$. Afterwards, the bottles containing the hybrid gel were frozen and stored at $-20{ }^{\circ} \mathrm{C}$ for $60 \mathrm{~h}$. Subsequently, the frozen bottles were immersed in liquid nitrogen at $-196{ }^{\circ} \mathrm{C}$ for 20 minutes before being placed immediately into the freeze drying apparatus (Model: K105 - Company Liotop - SP/Brazil) for $48 \mathrm{~h}$, and the temperature of the condenser was $-98^{\circ} \mathrm{C}$.

\section{Scanning electron microscopy (SEM)}

The microstructure of each material was observed using scanning electron microscopy (SEM-FEI-Inspect-S50/Czech Republic).
The scaffolds were immersed in liquid nitrogen and fractured to analyze the morphology of the porous structure. The fractured surface was coated with carbon (SPI/ Supplies-USA). The porous scaffolds are flexible behavior; therefore, the sample preparation process can deform the original structure of the scaffolds. Consequently, liquid nitrogen was used to retain the configuration of the structure during the fracturing process. The porosity and pore size of the scaffolds were determined using the following analytical techniques: (a) a qualitative assessment of the scanning electron microscopy (SEM) images; (b) a quantitative assessment obtained using microtomography $(\mu \mathrm{CT})$; (c) an Archimedes Balance was used to obtain the apparent porosity. The apparent porosity refers to the open pores present in the material, while the total porosity corresponds to the volume occupied by both open and closed pores (Reis, 2007). The Archimedes method is based on the principle that immersing a solid with certain bulk (B) displaces an amount of fluid equal to the bulk of the fluid when immersed. This technique measures the mass of the dry scaffold sample ( $\mathrm{M} \mathrm{dr}$ ), the mass of the sample saturated with liquid (M sat) and the mass of the sample submerged in liquid (M sub). ${ }^{23}$ The following equation is used to calculate the apparent porosity (open pores) that represents pores accessible to the fluid used in the test, and the total porosity represents open and closed pores in the material:

$$
\text { Apparent Porosity }(\%)=(\mathrm{M} \text { sat }-\mathrm{M} \text { dr }) /(\mathrm{M} \text { sat }-\mathrm{M} \text { sub }) \times 100
$$

\section{Evaluation by Micro-computed tomography $(\mu C T)$}

The equipment used to analyze the porosity was a Skyscan/Bruker - Model 1174 (Belgium). The samples are fixed directly on the sample ports equipment $\mu \mathrm{CT}$ using a mass of dental shape. The data were acquired under the following conditions: a spatial Resolution of 2 $\mu \mathrm{m}$, a tube voltage of $45 \mathrm{kV}$, scanning at $180^{\circ}$, no filter, 3 frames for media, a random motion of 5 and a rotation step of 0.25 .

\section{Compressive strength tests}

The scaffolds were submitted to a compression assay to assess the strength limits and deformation. Cylindrical scaffolds $18 \mathrm{~mm}$ in diameter and $10 \mathrm{~mm}$ high were submitted to a test with a preestablished end. Three units of each type of scaffold were tested. The tests were performed in an Instron model (EMIC DL 3000) using a load cell of $200 \mathrm{~N}$, a test speed of $0.5 \mathrm{~mm} / \mathrm{min}$ and a test temperature of $26 \pm 2{ }^{\circ} \mathrm{C}$. The compression tests were performed according to ASTM D $695 .^{24}$

\section{RESULTS AND DISCUSSION}

\section{Qualitative assessment of the scaffolds}

The scaffolds containing $10 \mathrm{wt} \%, 20 \mathrm{wt} \%$ and $30 \mathrm{wt} \%$ of BG and those containing $1 \mathrm{wt} \%, 3 \mathrm{wt} \%, 5 \mathrm{wt} \%$ and $10 \mathrm{wt} \%$ of BGNP presented an intact and solid structure on their external walls, while the interior had a high porosity. In general, the structure of the scaffolds after lyophilization remained without fractures or cracks, with few variations in their final size $(10 \mathrm{~mm} \times 18 \mathrm{~mm})$. The scaffolds had a cylindrical and symmetric configuration (Figure 1).

During this study, the porosity of the scaffolds was evaluated qualitatively by SEM. Therefore, the configuration, preferential alignment of the crystals of frozen liquid, presence of interconnectedness and appearance of the walls of the pores were evaluated. The pore size and the total percentage of pores in the scaffolds containing $0 \mathrm{wt} \%, 10$ $\mathrm{wt} \%$ and $20 \mathrm{wt} \%$ were obtained using micro-computed tomography $(\mu \mathrm{CT})$. However, this method could not measure the total porosity of the scaffold containing $30 \mathrm{wt} \%$ of bioactive glass. 

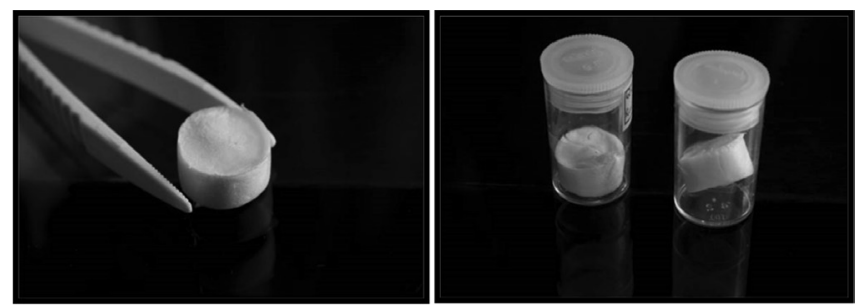

Figure 1. Photographs of $10 \mathrm{~mm} \times 18 \mathrm{~mm}$ samples of Chi-BG and Chi-BGNP scaffolds

\section{Morphology and porosity of the Chi-BG hybrid scaffolds}

The morphology of the scaffolds with $0 \mathrm{wt} \%, 10 \mathrm{wt} \%, 20 \mathrm{wt} \%$ and $30 \mathrm{wt} \%$ of bioactive glass was obtained by SEM, revealing significant differences in the structure of the pores in these scaffolds (Figure 2). The chitosan scaffold (Figure $2 \mathrm{a}$ ) contained non-uniform pores. In the scaffold containing $10 \mathrm{wt} \% \mathrm{BG}$, the pores are more regular and uniform (Figure 2b). In the scaffold with $20 \mathrm{wt} \%$ of BG the pores are also highly uniform but were also slightly elongated and becoming more lamellate (Figure 2c). In the scaffold containing $30 \mathrm{wt} \%$ of BG, the pores are more uniform and defined in certain regions, but other regions contain elongated pores or pores that have nearly collapsed (Figure 2d). In general, all of the scaffolds had a wall with a porous structure when sliced thickly. All compositions of the scaffolds contained some interconnectivity, even when few cavities were observed; this quality was more pronounced in scaffolds containing $10 \mathrm{wt} \%$ and $20 \mathrm{wt} \%$ of BG. Therefore, these materials are appropriate for cell growth and proliferation due to the uniform, isotropic morphology and interconnected nature.

The total porosity obtained by $\mu \mathrm{CT}$ for the scaffold without glass (0 wt\% BG) was $96 \pm 0.4 \%$ (Table 1 ), as expected due to its high liquid content. The size distribution of the pores showed that $80 \%$ of the pores were between 50 and $80 \mu \mathrm{m}$ in size; the majority of the pores were smaller than $100 \mu \mathrm{m}$, and the rest of pores included approximately $20 \%$ smaller than $50 \mu \mathrm{m}$ and larger than $80 \mu \mathrm{m}$. As previously described, this range of values contains the variations in pore size necessary for a good performance during tissue engineering.

The percentage of interconnectedness was not quantified by $\mu \mathrm{CT}$; therefore, the results were identified only by SEM images; due to their high degree of anisotropy, the presence of any interconnectedness in the chitosan scaffolds remains unknown. The apparent porosity of comparatively was also measured, revealing significant differences in the two techniques, specifically $\mu \mathrm{CT}$ (total porosity) and the Archimedes Balance (apparent porosity).

In scaffolds with $10 \mathrm{wt} \%, 20 \mathrm{wt} \%$ and $30 \mathrm{wt} \%$ of glass, the pore configurations varied; the region near the surface of the scaffold was denser, while the interior contained a more porous material. Typically, for highly porous samples (> 64\%), the microstructure becomes almost cellular (interconnectedness with walls of similar dimensions). ${ }^{15}$ The walls can be very thin $(<5 \mu \mathrm{m})$ for high cooling rates $\left(>5^{\circ} \mathrm{C} / \mathrm{min}\right)$, and the thickness can also be homogenous throughout the scaffold structure. The first zone of the sample (dense) is in contact with the cooling source; specifically, the surface experiences a higher rate of freezing and heat diffusion must occur. Therefore, an unstable cell morphology occurs at the freezing interface, resulting in poor interconnectedness in pores and the formation of dense material. The differences that occur in the morphologies of the pores in the scaffolds containing $10 \mathrm{wt} \%$ and $20 \mathrm{wt} \%$ of BG relative to the chitosan scaffold, which exhibits an undefined morphology, are most likely related to the glass added to its structure because all of the scaffolds underwent identical synthetic and lyophilization processes. The hybrid formed from chitosan and silica exhibits an increased interfacial interaction (Figure 3 ), which may improve the mechanical properties. The interactions between the chitosan and the TEOS reveal the formation of hydrogen bonds between the amide groups on chitosan and the ionic silanol groups, connections between the amines from chitosan and the silanols and covalent bonds generated after the esterification of the hydroxyl groups on chitosan and the networked silanol groups on the silica. ${ }^{25}$
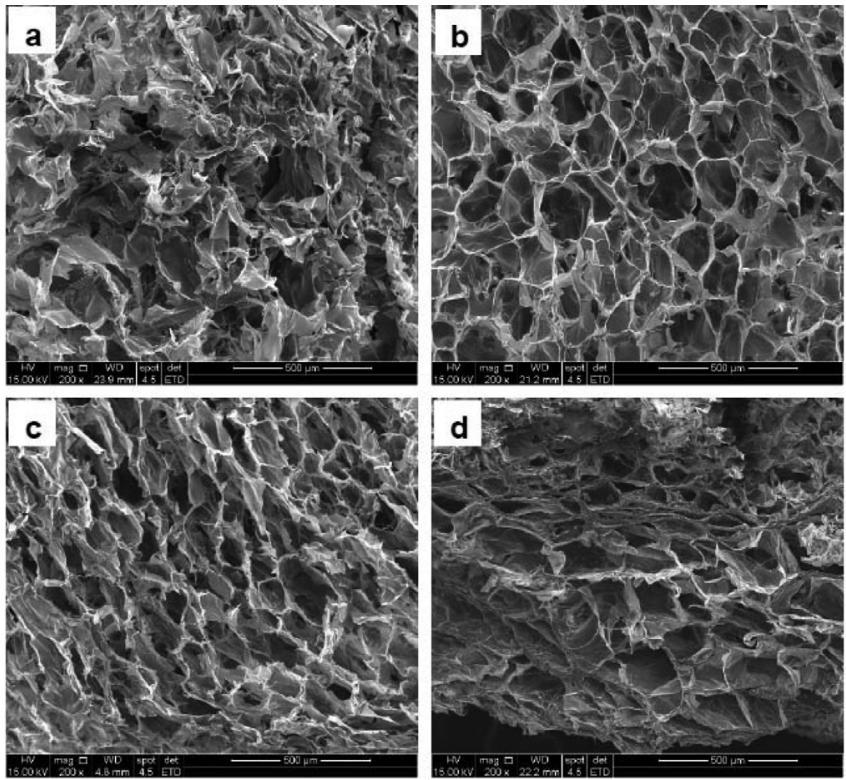

Figure 2. SEM images of the porous structures of the scaffolds containing $0 w t \%(a), 10 w t \%(b), 20 w t \%(c)$ and $30 w t \%(d)$ of BG at 200x magnification $(a-d)$

\section{Morphology and porosity of the Chi-BGNP nanocomposites scaffolds}

The pore structure of the samples containing $1,3,5$ and 10 wt $\%$ of BGNP is shown in Figures $4 a, 4 b, 4 c$ and $4 d$, respectively. In the nanocomposite scaffolds, the apparent porosity was obtained using an Archimedes Balance. As expected, the chitosan scaffolds

Table 1. Percentage porosity and pore size obtained for hybrids

\begin{tabular}{lcccc}
\hline \multirow{2}{*}{ Sample (wt $\%)$} & \multicolumn{2}{c}{ Porosity } & Range of predominant pore size & Range of pore size \\
\cline { 2 - 5 } & Apparent $(\%)$ & Total $*(\%)$ & $*(\mu \mathrm{m})$ & $* *(\mu \mathrm{m})$ \\
\hline Qui 0\% & $72 \pm 2$ & $96.0 \pm 0.4$ & $50-80$ & $63-192$ \\
Qui 10\% BG & $64 \pm 2$ & $96.0 \pm 0.4$ & $46-84$ & $64-213$ \\
Qui 20\% BG & $55 \pm 6$ & $95.7 \pm 0.7$ & $50-110$ & $90-105$ \\
Qui 30\% BG & $48 \pm 2$ & $\mathrm{x}$ & $\mathrm{x}$ & $122-227$ \\
\hline
\end{tabular}

*Obtained by $\mu \mathrm{CT}$. **Obtained by SEM. 
<smiles>COC(O)C(O)C(O)C(OC(NC(C)=O)C(O)CO)C(N)O</smiles>

Chitosan

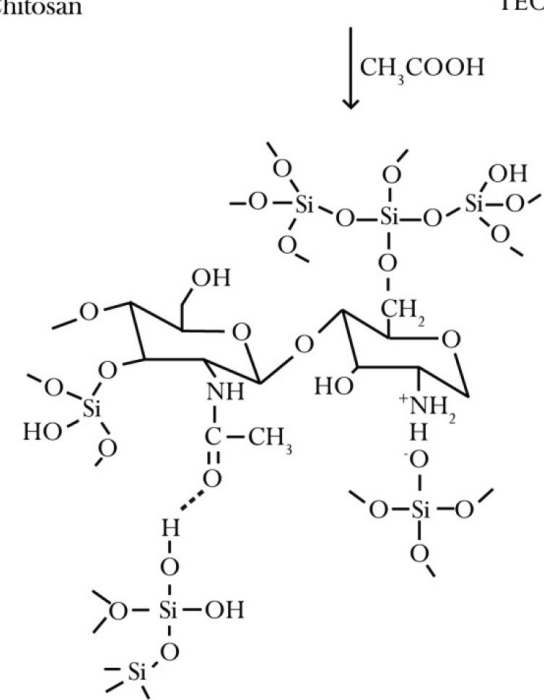

Figure 3. Schematic suggestion of the chitosan and the precursor TEOS interaction

containing $1 \mathrm{wt} \%$ of BGNP (Figure 4a) had a high apparent porosity of approximately $62 \%$ due to the high volume of liquid contained in their structures (Table 2). The surfaces of these scaffolds exhibit a morphology containing regular pores with a spherical appearance/ cellular and some regions of interconnectivities when magnified (Figure $4 \mathrm{~b}$ ). The surfaces of the pore walls were homogenous and smooth. The range of pore sizes obtained in the region analyzed by SEM was between $130 \mu \mathrm{m}$ and $330 \mu \mathrm{m}$.
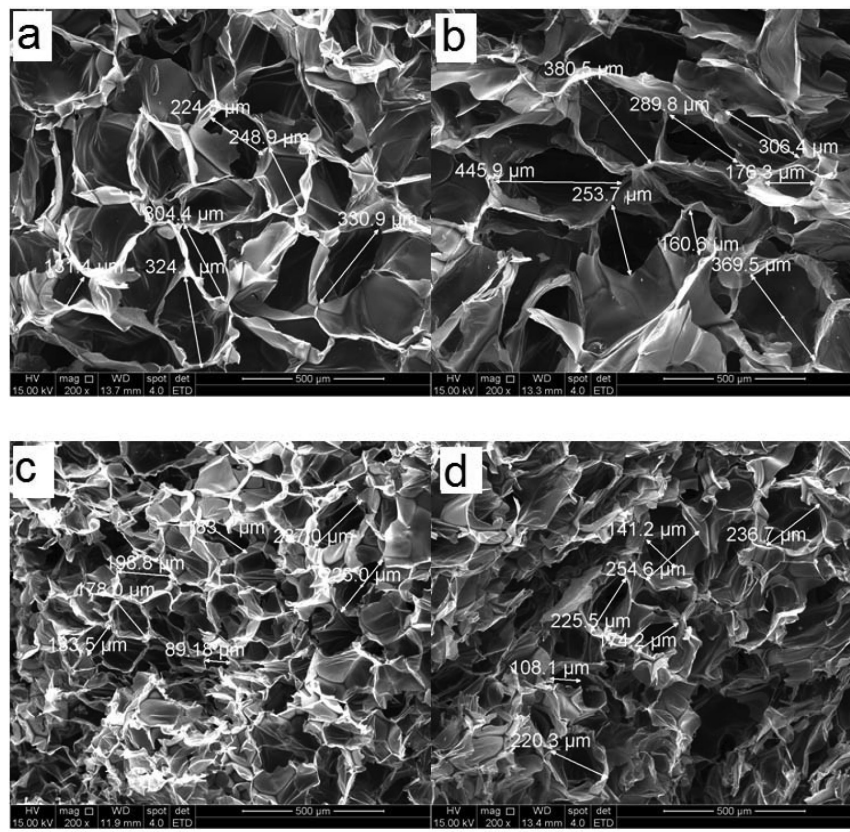

Figure 4. SEM images of the porous scaffolds containing $1 w t \%(a), 3 w t \%$ (b), $5 w t \%(c)$ and $10 w t \%(d)$ of BGNP at 200x magnification (a-d)
Table 2. Percentage porosity and pore size range obtained for nanocomposites

\begin{tabular}{ccc}
\hline Sample & Apparent Porosity $(\%)$ & Range of pore size $(\mathrm{mm})$ \\
\hline Qui 0\% & $72.1 \pm 2.0$ & $63-192$ \\
Qui 1\%BGNP & $78.5 \pm 2.9$ & $131-331$ \\
Qui 3\%BGNP & $77.7 \pm 6.1$ & $161-446$ \\
Qui 5\%BGNP & $63.4 \pm 2.3$ & $89-237$ \\
Qui10\%BGNP & $62.3 \pm 2.3$ & $108-255$ \\
\hline
\end{tabular}

* Obtained by SEM.

\section{Mechanical Properties}

\section{Compressive tests for the Chi-BG hybrid scaffolds}

The scaffolds containing chitosan and 0,10,20 and $30 \mathrm{wt} \%$ of bioactive glass reticulated with glutaraldehyde were assayed; their stress-strain behavior is shown in Figure 5a. The curves show that the behavior of the material has been modified such that its composition was changed after adding bioactive glass. Increasing the glass content of the scaffold changes the mechanical properties, proving that the compressive strength increases in the glass-containing polymeric material. However, an excess of glass decreases the strength and the ability to resist deformation. The tests revealed a threshold of strength resisting compression that demonstrated, values well below the limit for trabecular bone, which ranges from 2-12 MPa, for the scaffold containing 10, 20 and $30 \mathrm{wt} \%$ of BG; however, the bioactive glass increases the strength of the hybrid. The optimal glass content is $20 \mathrm{wt} \%$, which increases the strength without dramatically decreasing the percentage of deformation for the Chi-BG hybrid scaffold.

The average values obtained from the strength and maximum deformation from compression show that the scaffold containing pure chitosan has a maximum strength toward compression of $0.011 \mathrm{MPa}$ and a maximum deformation of 59\%. The scaffolds with $10 \mathrm{wt} \%$ of bioactive glass increased their compression strength, reaching approximately $0.019 \mathrm{MPa}$, while scaffolds with $10 \mathrm{wt} \%$ of glass also increased their deformation, reaching $68 \%$.

The scaffolds with $20 \mathrm{wt} \%$ of glass increase their maximum strength limit, reaching $0.041 \mathrm{MPa}$, but decrease in deformation ability to approximately $48 \%$. The scaffold with $30 \mathrm{wt} \%$ of bioactive glass decreases in strength to compression, dropping to approximately $0.037 \mathrm{MPa}$, and its deformation decreases to $32 \%$.

\section{Compressive Tests for the Chi-BGNP scaffolds}

The stress $\mathrm{x}$ strain behavior was determined for the nanocomposite chitosan scaffolds with 1, 3, 5 and $10 \mathrm{wt} \%$ of BGNP (Figure 5b) reticulated with glutaraldehyde. The curves revealed that the material changed its mechanical behavior directly with its composition.

The scaffolds containing 1 and $3 \mathrm{wt} \%$ of BGNP attained values of 0.05 and $0.04 \mathrm{MPa}$, respectively, for the maximum strength against compression, demonstrating the effect of the nanoparticles toward strengthening the nanocomposite scaffolds. Furthermore, the scaffolds with 5 and $10 \mathrm{wt} \%$ of BGNP increased in maximum strength toward compression relative to the other levels, reaching 0.12 and $0.11 \mathrm{MPa}$, respectively; their maximum capacity for deformation also increased, reaching $71 \%$ and $60 \%$, respectively.

Table 3 compares the mechanical behavior of the hybrid and nanocomposite scaffolds. The stress $\mathrm{x}$ strain curves for the scaffolds containing bioactive glass nanoparticles (BGNP) revealed their strength properties. The nanocomposites containing 1, 3, 5 and 10 $\mathrm{wt} \%$ of BGNP exhibited highest maximum compressive strain relative to the other Chi-BG scaffolds. However, the values for the maximum deformation obtained for the nanocomposite scaffolds were not far from the results obtained from the hybrid scaffolds. 

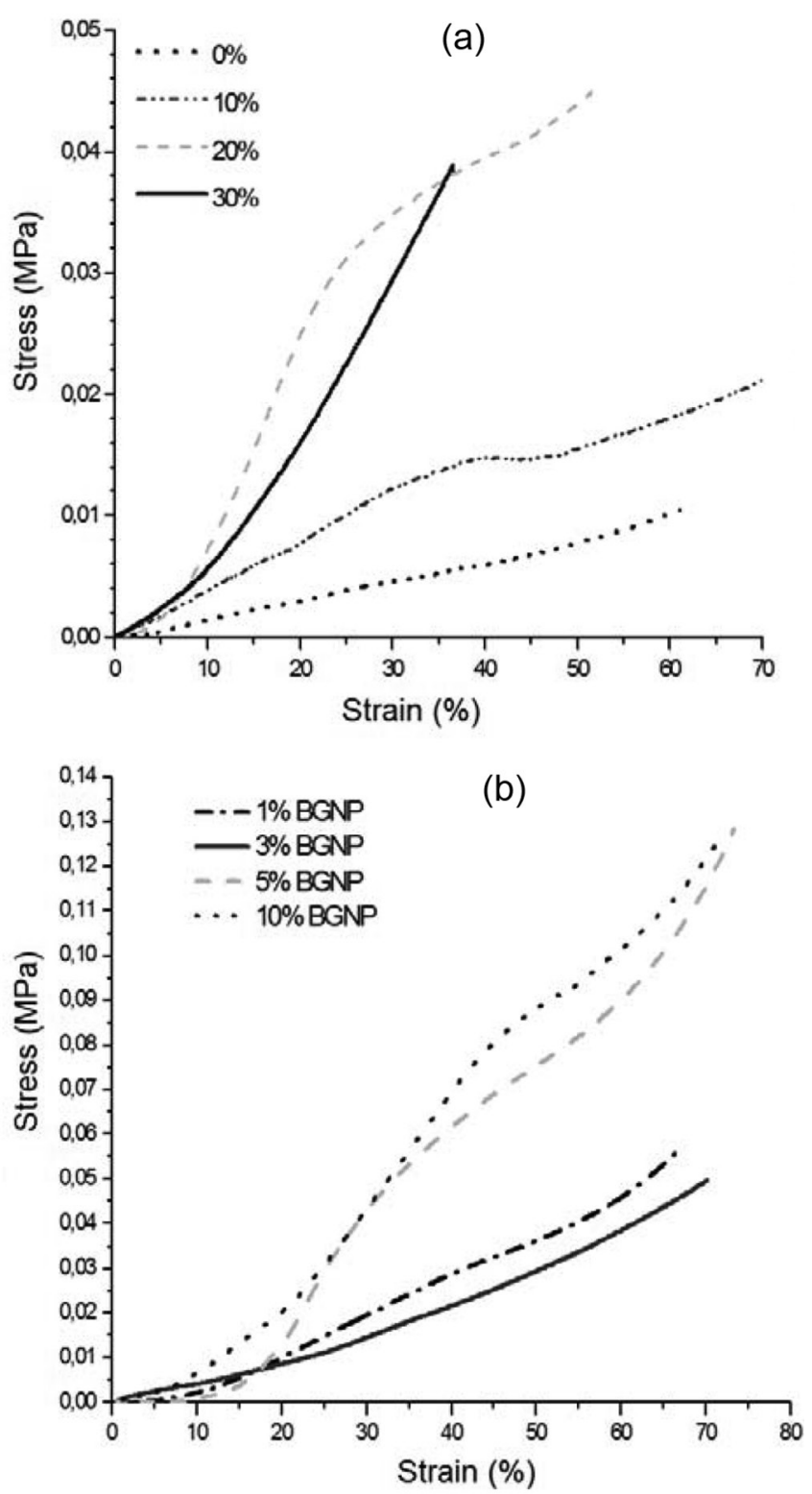

Figure 5. Stress $\times$ strain curves obtained during a compressive test with the Chi-BG (a) and Chi-BGNP (b) scaffolds

Table 3. Comparison of mean maximum stress strain values for the hybrid scaffolds and nanocomposites

\begin{tabular}{ccc}
\hline $\begin{array}{c}\text { Samples } \\
(\text { wt } \%)\end{array}$ & $\begin{array}{c}\text { Maximum compressive } \\
\text { stress }(\mathrm{MPa})\end{array}$ & $\begin{array}{c}\text { Maximum compressive } \\
\text { strain }(\%)\end{array}$ \\
\hline Chi 0\% & $0.011 \pm 0.001$ & $59 \pm 2$ \\
Chi 10\% BG & $0.019 \pm 0.002$ & $68 \pm 1$ \\
Chi 20\% BG & $0.041 \pm 0.006$ & $48 \pm 2$ \\
Chi 30\% BG & $0.037 \pm 0.005$ & $32 \pm 2$ \\
Chi 1\% BGNP & $0.051 \pm 0.003$ & $65 \pm 6$ \\
Chi 3\% BGNP & $0.049 \pm 0.004$ & $68 \pm 4$ \\
Chi 5\% BGNP & $0.125 \pm 0.02$ & $71 \pm 3$ \\
Chi 10\% BGNP & $0.118 \pm 0.03$ & $69 \pm 2$ \\
\hline
\end{tabular}

\section{CONCLUSIONS}

The compressive tests with the porous scaffolds revealed a strength limit well below that of trabecular bone, which ranges from 2 Maximum compressive to $12 \mathrm{MPa}$. However, the bioactive glass increases the strength of the hybrids, especially when delivered as nanoparticles. Therefore, the material produced using the method reported here is superior to that produced through the conventional synthetic route, which incorporates the bioactive glass through a sol-gel method. All of the scaffolds attained a high porosity with pore sizes between 50 and $227 \mu \mathrm{m}$, thus meeting the requirements for growing tissue.

\section{ACKNOWLEDGMENTS}

The authors thank CNPq, CAPES and FAPEMIG for their financial support of this work.

\section{REFERENCES}

1. Mota, J.; Yu, N.; Caridade, S. G.; Luz, G. M.; Gomes, M. E.; Reis, R. L.; Jansen, J. A.; Walboomers, X. F.; Mano, J. F.; Acta Biomater. 2012, $8,4173$.

2. Boccaccini, A.; Mano, J. F.; Compos. Sci. Technol. 2010, 70, 1764.

3. Ostomel, T. A.; Shi, Q.; Tsung, C.; Liang, H.; Stucky, G. D.; Small 2006, 11,1261

4. Oliveira, A. A. R.; Carvalho, B. B.; Mansur; H. S.; Pereira, M. M.; Mater. Lett. 2014, 133, 44.

5. Sen, L.; Ionescu, C.; Pike, K. J.; Smith, M. E.; Jones, J. R.; J. Mater. Chem. 2009, 19, 1276.

6. Guarino, V.; Causa, F.; Ambrosio, L.; Expert Rev. Med. Devices 2007, 4,405 .

7. Rezwan, K. K.; Chen, Q. Z.; Blaker, J. J.; Boccaccini, A. R.; Biomaterials 2006, 27, 3413.

8. Palin, E.; Liu, J.; Webster, T. J.; Nanotechnology 2005, 16, 1828.

9. Yao, J.; Radin, S.; Leboy, P. S.; Ducheyne, P.; Biomaterials 2005, 26, 1935.

10. Kay, S.; Thapa, A.; Haberstroh, K. M.; Webster, T. J.; Tissue Eng. 2002, 8,753 .

11. Webster T. J.; Siegel. R. W.; Bizios, R.; Scr. Mater. 2001, 44, 1639.

12. Roco, M.; J. Nanopart. 1999, $1,1$.

13. Jones, J.; Ehrenfried, L. M.; Hench, L. L.; Biomaterials 2006, 27, 964.

14. Thomson, R.; Shung, A. K.; Yaszemski, M. J.; Mikos, A. G. In Principles of Tissue Engineering; Lanza, R., Langer, R., Chick, W., eds.; Academic Press: New York, 1997, pp. 263-272.

15. Deville S.; Saiz, E.; Tomsia, A. P.; Biomaterials 2006, 27, 5480.

16. Abdelwahed, W.; Degobert, G.; Stainmesse, S.; Fessi, H.; Adv. Drug Delivery Rev. 2006, 58, 1688.

17. Dorj, B.; Park, J. H.; Kim, H. W.; Mater. Lett. 2012, 73, 119.

18. Peter, M.; Kumar, P. T. S.; Binulal, N. S.; Nair, S. V.; Tamura, H.; Jayakumar, R.; Carbohydr. Polym. 2009, 78, 926.

19. Hong, Z.; Reis, R. L.; Mano, J. F.; Acta Biomater. 2008, 4, 1297.

20. Roohani-Esfahani, S. I.; Nouri-Khorasani, S.; Lu, Z. F.; Appleyard, R. C.; Zreiqat, A. H.; Acta Biomater. 2011, 7, 1307.

21. Peter, M.; Binulal, N. S.; Soumya, S.; Nair, S. V.; Furuike, T.; Tamura, H.; Jayakumar, R.; Carbohydr. Polym. 2010, 79, 284.

22. Cai, X.; Tong, H.; Shen, X.; Chen, W.; Yan, J.; Hu, J.; Acta Biomater. 2009, 5, 2693.

23. Ho, S.; Hutmacher, D.; Biomaterials 2006, 27, 1362.

24. ASTM D 695-Standard Test Method for Compressive Properties of Rigid Plastics.

25. Al-Sagheer, F.; Muslim S.; J. Nanomater. 2010, 2010, 1. 